\title{
A ATUAÇÁO PENAL DA DEFENSORIA PÚBLICA COMO CUSTOS VULNERABILIS: UMA MANIFESTAÇÁO DO GARANTISMO JURÍDICO
}

\author{
THE CRIMINAL ATTRIBUTION OF THE PUBLIC DEFENDER'S \\ DEPARTMENT AS CUSTOS VULNERABILIS: A MANIFESTATION OF THE \\ GUARANTEEISM THEORY
}

\author{
Fabiana Diogenes ${ }^{\mathrm{I}}$ \\ Nestor Eduardo Araruna Santiago ${ }^{\text {II }}$
}

${ }^{\text {I } U n i v e r s i d a d e ~ d e ~ F o r t a l e z a, ~ F o r t a l e z a, ~ C E, ~}$
Brasil. E-mail: fabianamddiogenes@gmail.
com

II Universidade de Fortaleza, Fortaleza,

CE, Brasil. Doutor em Direito. E-mail: nestoreasantiago@gmail.com
DOI: http://dx.doi.org/10.31512/rdj.v21i40.355

Recebido em: 26.03.2021

Aceito em: 13.04.2021
Resumo: No presente artigo, estudou-se a teoria do garantismo jurídico, que propôs uma releitura do modelo positivista então vigente, com o objetivo de conferir primazia à igualdade jurídica e aos direitos fundamentais, relacionando-a com as atribuiçóes conferidas à Defensoria Pública de promoçáo dos direitos humanos e defesa dos vulneráveis. Mediante pesquisa pura, qualitativa e bibliográfica, demonstrou-se que o processo de expansão do direito de acesso à justiça resulta na necessidade de uma nova concepção da atuação da Defensoria Pública, conferindo-lhe, além das funções já estabelecidas, uma atribuição interveniente ou complementar, fundamentada no interesse constitucional da instituição. Diante da situaçáo de vulnerabilidade em que figura o indivíduo processado criminalmente, bem como em razáo da supremacia do Estado Acusador nas regras processuais penais pátrias, vislumbrou-se que a participação do órgão defensorial como custos vulnerabilis funciona como um relevante instrumento de efetivação dos direitos do acusado, colocando o Estado Acusador, Estado Julgador e Estado Defensor em posiçôes de igualdade.

Palavras-chave: Garantismo jurídico. Estado Democrático de Direito. Defensoria Pública. Vulnerabilidade jurídica. Custos vulnerabilis.

Abstract: In this article, the guaranteeism theory was studied, which proposed a re-reading of the positivist model then in force, with the aim of giving primacy to legal equality and fundamental rights, relating it to the attributions granted to the Public Defender's Department to promote human rights and the defense of the vulnerable. Through pure, qualitative and bibliographical research, it has been demonstrated that the process of expanding the right of access to justice results in the need for a new conception of the Public Defender's Department, conferring on it, besides the already established functions, an intervening or complementary attribution, 
based on the constitutional interest of the institution. In view of the situation of vulnerability in which the individual is criminally prosecuted, as well as the supremacy of the Accusatory State in the brazilian's criminal procedural rules, it was envisaged that the participation of the Public Defender's Department as custos vulnerabilis functions as a relevant instrument for the effective realization of rights of the accused, placing the Accuser State, State Judge and State Defender in equal positions.

Keywords: Guaranteeism. Democratic State of Law. Public Defender's Department. Legal Vulnerability. Custos vulnerabilis.

\section{CONSIDERAÇÓES INICIAIS}

O presente trabalho apresenta uma análise da teoria do garantismo jurídico e suas inovaçôes ao modelo positivo então vigente, com foco na visão substancial da democracia proposta pelo modelo jurídico, por meio da prevalência da igualdade jurídica e dos direitos fundamentais previstos no ordenamento jurídico.

Diante da necessidade de fortalecimento do Poder Judiciário e das instituições estatais voltadas à concretização de direitos para a aplicação do modelo garantista, estudarse-á a compatibilidade da atuação da Defensoria Pública com o garantismo, como instituição constitucionalmente incumbida da promoção dos direitos humanos e como instrumento do regime democrático.

Sobre o tema, dissertar-se-á sobre a atuação do Defensor Público no processo penal como instrumento de acesso à justiça, transcendendo a mera atuação em favor dos desprovidos de recursos financeiros, diante da existência de outras modalidades da situação de vulnerabilidade, notadamente se reconhecendo a vulnerabilidade da pessoa objeto de um processo criminal ou presa, sendo, neste último caso, reconhecida expressamente a Defensoria Pública como órgão da execução penal.

Assim, diante do caráter expansivo do acesso à justiça, que se concretiza através da defesa efetiva dos que estão em situação de vulnerabilidade, estudar-se-á a atuação da Defensoria Pública como custos vulnerabilis no âmbito do processo penal, por meio da qual a instituição se apresenta como parte interveniente no feito, de maneira coadjuvante ao advogado de defesa, a fim de resguardar os interesses que lhes são atribuídos constitucionalmente.

A pesquisa dará especial destaque à ação interveniente do Defensor Público no âmbito processual penal, levando-se em consideração o caráter de hipervulnerabilidade da pessoa em custódia estatal, bem como o desequilíbrio entre o Estado Acusador e o Estado Defensor, o que demanda uma especial atuação do órgão defensorial.

O presente artigo, portanto, busca fornecer elementos que permitam verificar a necessidade de releitura da atuação da Defensoria Pública, diante do fenômeno expansivo 
do acesso à justiça, para compreensão de sua atribuição como custos vulnerabilis, atuação do Defensor interveniente que tem como objetivo reestabelecer a paridade das armas e promover a igualdade jurídica no âmbito do processo penal.

\section{O GARANTISMO JURÍDICO E O ESTADO CONSTITUCIONAL DE DIREITO}

As bases de fundação da doutrina jurídico-política denominada como garantismo jurídico remonta aos ideais iluministas, que sustentavam a capacidade crítica do homem na construção do processo humanizador, negando a redução do homem a um caráter supérfluo (CARVALHO, 2011, p. 78), servindo como limite à submissão do indivíduo face ao poder.

Modernamente, a teoria foi elaborada na Itália dos anos sessenta, em um contexto jurídico em que se tentou combater a conturbação política com legislaçôes emergenciais, gerando uma reação jurídica com o fito de observância dos direitos e garantias individuais e limitação do poder punitivo estatal (IPPOLITO, 2011, p. 36).

O modelo garantista, que tem como principal expoente Luigi Ferrajoli, por meio de sua obra "Direito e Razão: Teoria do Garantismo Penal", apresentou, como inovação central ao modelo positiva então vigente, uma dupla análise da norma jurídica ao Direito, refutando a mera aferição da conformidade da norma com o processo legislativo posto, ou seja, em seu aspecto formal, o que denominou como vigência (FERRAJOLI, 1992, p. 122).

Exigiu-se, além do controle da vigência da norma, a análise da compatibilidade desta com normas substanciais, tais como a igualdade material e os direitos fundamentais (FERRAJOLI, 1992, p. 122). Assim, na hipótese de norma que apresente violação a direito individual ou social, deve-se reconhecer sua invalidade.

Partindo deste pressuposto, passa-se a entender que a legitimação do Estado Democrático de Direito deve suplantar a mera democracia formal, vinculada à vontade da maioria, para alcançar a democracia material, na qual os direitos fundamentais devem ser respeitados, efetivados e garantidos, sob pena da deslegitimação das instituições estatais (ROSA, 2003, p. 20).

Neste aspecto, o Estado de Direito se contrapóe ao Estado absoluto, seja ele autocrático ou democrático, dada a impossibilidade de uma maioria decidir pela violação do direito de uma minoria, ou até mesmo de um único indivíduo (CADERMATORI, 2006, P. 151). Assim, nem sobre tudo se pode decidir, quando tratamos de direitos de liberdade e, por outro lado, nem sobre tudo se pode deixar de decidir, já que o legislador ordinário tampouco pode se imiscuir da obrigação de promoção dos direitos sociais.

Neste contexto, o modelo garantista propõe o fortalecimento do Poder Judiciário, por meio de sua legitimação democrática, derivada da sua função de garantia dos direitos fundamentais (FERRAJOLI, 1992, p. 123). Assim, o juiz, ao atentar para a validade substancial da norma, é visto como agente de consciência da realidade que o circunda, dotando texto legal de significado (MARTINS, 2016, p. 571). 
Através do garantismo jurídico, os poderes estatais passam a ser submetidos ao crivo de duas fontes de legitimação: a tradicional legitimação formal, nos termos do princípio da legalidade e de sujeição à lei, e a legitimação substancial, com o reconhecimento da funcionalização do Estado a serviço da garantia dos direitos fundamentais dos cidadãos, por meio da incorporação às Constituiçóes dos deveres públicos de proibiçóes de lesionar os direitos de liberdade e de satisfazer os direitos sociais.

Diante disto, verifica-se que, em que pese a ideia do garantismo ser tradicionalmente vinculada ao Direito Penal, neste ramo não se exaure, alcançando um status de Teoria Geral de Direito (SANTIAGO, SILVA, 2012, p. 55). Funciona, inclusive, como medida de análise do grau de legitimidade estatal, na medida em que "propóe um modelo ideal de Estado de Direito, ao qual os diversos Estados Reais de Direito devem aproximar-se, sob pena de deslegitimação" (CADEMARTORI, 2006, p. 91).

Verifica-se, portanto, que o presente modelo se aplica ao estado constitucional, como instrumento de concretização dos direitos fundamentais e à própria consolidação dos regimes democráticos (TRINDADE, 2013, online). Assim, garantismo e direitos fundamentais são aspectos similares, e estarão presentes sempre que se verificar o Estado Constitucional de Direito (SANTIAGO, SILVA, 2012, p. 58).

Neste aspecto, entende-se que, no contexto de implantação do Estado Constitucional de Direito, faz-se inevitável não apenas o fortalecimento do Poder Judiciário, mas das instituiçôes estatais voltadas à efetivação dos direitos fundamentais previstos. Assim, cabe destacar a Defensoria Pública, como instituição criada no contexto de busca ao acesso à justiça e à igualdade jurídica das partes.

\section{A DEFENSORIA PÚBLICA E O MODELO GARANTISTA}

Partindo-se do pressuposto de concretização do modelo garantista, por meio da funcionalização do Estado à serviço da garantia e efetivação dos direitos fundamentais dos cidadáos, cabe destacar o direito de acesso à justiça, o qual se consubstancia não apenas na proibição ao Estado de estabelecer barreiras ao exercício do direito de ação, mas também na obrigaçáo estatal positiva de criar mecanismos para que todos tenham acesso satisfatoriamente ao sistema de justiça (ROGER, 2017, p. 190).

Neste aspecto positivo, verifica-se que os custos relacionados às despesas processuais e representação por profissional devidamente qualificado se consubstanciam em limites ao acesso à justiça tão efetivos aos pobres como barreiras legais ao exercício de ação, já que a simples proclamação de um direito sem a disponibilização de um instrumento para o exercício nada mais é que sua negação. 
E mais, a hipossuficiência do indivíduo muitas vezes o impede de se reconhecer como titular de um direito juridicamente exigível (CAPPELLETTI, GARTH, 1988, p. 8), mantendo-o alheio ao sistema de justiça, sem ao menos identificar sua exclusão.

Diante disto, Cappelletti e Garth, na obra "Acesso à Justiça" (1988, p. 12), estabelecem como primeira onda renovatória da justiça a assistência judiciária aos pobres, como segunda onda renovatória de justiça a tutela coletivizada de direitos ou direitos coletivos e, por fim, a terceira onda de acesso à justiça relacionada à solução extrajudicial de conflitos.

Rocha (2016, p. 53) aponta que lamentavelmente os autores não tiveram a oportunidade de testemunhar a construção da Defensoria Publica, entretanto, em uma análise exegética, a instituição, na condição de autônoma, una e indivisível, se apresenta como um instrumento eficaz aos obstáculos por eles descritos ao acesso à justiça.

A Defensoria Pública surgiu com a inauguração da nova ordem constitucional brasileira, a partir da qual se passou a dar primazia aos direitos fundamentais, constitucionalizando garantias de minorias antes não (ou pouco) resguardadas pelos ordenamento legal. Diante do reconhecimento da necessidade de efetivação dos direitos das camadas da sociedade em vulnerabilidade, paulatinamente diversas emendas foram adicionadas ao texto constitucional, com o fito de fortalecer a atuação dos Defensores Públicos.

Por último, a Emenda Constitucional n. 80/2014, alterou o artigo 134 da Constituição Federal para reconhecer a instituição como expressão e instrumento do regime democrático, incumbindo-lhe, fundamentalmente, a orientação jurídica, a promoção dos direitos humanos e a defesa, em todos os graus, judicial e extrajudicial, dos direitos individuais e coletivos, de forma integral e gratuita, aos necessitados, na forma do inciso LXXIV, artigo $5^{\circ}$, Constituição Federal.

Assim, no cenário brasileiro, visualiza-se a Defensoria Pública como instrumento do Estado Democrático de Direito, em uma clara vinculação da instituição à aplicação do modelo jurídico garantista, na medida em que pauta sua atuação na aplicação dos direitos fundamentais das partes, notadamente no que concerne na persecução da igualdade jurídica (ARAÚJO, SANTIAGO, 2015, p. 72).

No contexto da busca pela isonomia, cabe destacar o âmbito processual penal, terreno fértil de aplicação do modelo garantista, diante da essencialidade dos direitos "em jogo", na medida em que o acusado, ao final do processo, pode ter suas liberdades cerceadas pelo Estado. Neste sentido, faz-se necessária a implementação de um sistema jurídico que priorize seus direitos e garantias individuais.

É neste contexto que se vislumbra a atuação da Defensoria Pública do âmbito criminal com o fito de que o acusado obtenha acesso satisfatório ao sistema de justiça, e não uma mera representação processual formal de legitimação do poder punitivo estatal.

Sobre o tema, Ferrajoli (2002, p. 275) disserta que a instituição representa um dos aportes mais significativos da experiência jurídica latino-americana, atendendo a diversas instâncias garantistas, sendo as de maior destaque no âmbito processual penal: 1) a confrontação 
de fato, e não apenas no plano normativo, das hipóteses trazidas pela acusação; 2) as liberdades fundamentais das pessoas em face dos poderes arbitrários; 3) a credibilidade da magistratura e a confiança a ele por parte dos cidadãos, através da absolvição do inocente, a qual não é menos relevante que a condenaçáo do culpado; 4) a paridade entre acusação e defesa, por meio de um efetivo contraditório; 5) a igualdade das pessoas frente à lei, não deixando sem defesa substancial aqueles que, por questôes econômicas, não possam constituir advogado de sua confiança; 6) corolário de presunção de inocência.

Portanto, com o fito de reequilibrar o embate de forças com a acusação, Ferrajoli defende a possibilidade de o Defensor Público atuar ao lado da defesa privada, potencializando a efetividade dos direitos do acusado (MAIA, SANTIAGO, 2019, p. 174).

Frise-se que a atuação do Defensor Público transcende o mero acesso à justiça do indivíduo sem recursos financeiros, atuando como agente de promoção dos direitos humanos e de redução das desigualdades sociais (MENDES, 2014, p. 123). Assim, trata-se de uma instituiçáo que tem sua atuaçáo em construção permanente na medida em deve se munir de todos os instrumentos para a persecução de seus fins constitucionalmente previstos.

Neste sentido, tem-se que a criação da Defensoria Pública foi inicialmente pensada para fins exclusivos de defesa do hipossuficiente na forma do inciso LXXIV, artigo $5^{\circ}$, Constituição Federal. Entretanto, passou-se a identificar determinados grupos sociais tidos por necessitados ou vulneráveis, independentemente de sua condição econômica, os quais necessitam de uma intervenção jurídica, sob pena de se verem privados dos seus direitos e alocados à margem do pacto social (FENSTERSEIFER, 2017, p. 51).

As Regras de Brasília sobre Acesso à Justiça das Pessoas em Condições de Vulnerabilidade (2008) estabelecem que "pessoas em condição de vulnerabilidade" são as "que, por razão da sua idade, gênero, estado físico ou mental, ou por circunstâncias sociais, econômicas, étnicas e/ou culturais, encontram especiais dificuldades em exercitar com plenitude perante o Sistema de Justiça os direitos reconhecidos pelo ordenamento jurídico”.

No mesmo sentido, ressalta Rocha (2016, p. 57) que a necessidade (vulnerabilidade) náo advém exclusivamente de questôes econômicas, mas de diversas outras questôes específicas do ser humano. Assim, se o Estado, através da Defensoria, não cuidar dessas situaçôes, estes indivíduos permanecerão em situação de invisibilidade (ROCHA, 2016, p. 58).

Neste sentido, o art. 4\% ${ }^{\circ}$ XI, da LC 80/94, com as alteraçôes trazidas pela Lei Complementar 132/2009, não estabeleceu um rol taxativo para definir os grupos vulneráveis, ao determinar que cabe à Defensoria Pública "exercer a defesa dos interesses individuais e coletivos da criança e do adolescente, do idoso, da pessoa portadora de necessidades especiais, da mulher vítima de violência doméstica e familiar e de outros grupos sociais vulneráveis que mereçam proteção especial do Estado.”

A título de ilustração, cite-se a atuação da Defensoria Pública do Estado do Ceará durante a Copa do Mundo de 2014 (ARAÚJO, SANTIAGO, 2015, p. 79), a qual se deu inclusive 
em favor de estrangeiros que visitavam o Brasil por ocasiáo dos jogos e por algum motivo foram detidos, pessoas presumivelmente com boas condiçôes econômicas, mas inegavelmente em condição de vulnerabilidade, por estarem presos em país estrangeiro e impossibilitadas de regressar ao seu país de origem.

Portanto, para além da perspectiva estritamente econômica, é fundamental para atender aos ditames constitucionais de forma plena a proteção especial de determinados indivíduos e grupos sociais em razáo da presunção da sua vulnerabilidade existencial por se enquadrarem em determinada situação de fato que não lhes permite exercerem os seus direitos com plenitude perante o Sistema de Justiça, o que faz com que seja atribuída à Defensoria Pública a tutela e promoção dos seus direitos (FENSTERSEIFER, 2017, p. 54).

É neste contexto que se passa a admitir a atuação da Defensoria Pública no processo criminal, diante da verificação da hipossuficiência jurídica do acusado, mesmo ausente a comprovação do requisito de insuficiência financeira, conforme será abordado no tópico a seguir.

\section{A VULNERABILIDADE DO ACUSADO NO PROCESSO CRIMINAL E A DEFENSORIA PÚBLICA}

O Pacto San José de Costa Rica, do qual o Brasil é signatário, garante a todo acusado o direito irrenunciável de ser assistido por um defensor proporcionado pelo Estado, remunerado ou não, caso ele próprio não nomeie defensor no prazo estabelecido por lei. Por outro lado, a Constituição Federal de 1988 garante, em seu artigo 5, VL, "aos litigantes, em processo judicial ou administrativo, e aos acusados em geral são assegurados o contraditório e ampla defesa, com os meios e recursos a ela inerentes".

Verifica-se da análise do mencionado dispositivo constitucional que não houve qualquer restrição à aplicação do contraditório apenas aos processos judiciais (FIRMO, SANTIAGO, 2015, p. 69). Pelo contrário, tendo em vista que no texto constitucional constou a expressão "acusados em geral", englobou, portanto, todo tipo de acusação, seja acusação formal em ação penal ou não (LOPES JR., 2014, p. 468).

Ademais disto, o contraditório deve ser estudado não só sob o ponto de vista formal, através da cientificação de atos processuais, participação em audiências, dentre outras formalidades, mas também materialmente, por meio da participação ativa da defesa da produção da decisão (FIRMO, SANTIAGO, 2015, p. 72).

A partir das reformas realizadas no Código de Processo Penal, notadamente com o advento da Lei 11.719/2008, o Defensor Público foi alçado a uma função típica de garantidor do princípio da ampla defesa e do contraditório (FERREIRA, PRADO, 2009, online), na medida em que se passou a admitir que caso o acusado, citado pessoalmente, deixe de oferecer defesa ou quando for citado ficticiamente para oferecer resposta à acusação imputada com a denúncia e 
não a oferece, deverá o juiz nomear defensor para oferecê-la, concedendo-lhe vista dos autos por $10(\mathrm{dez})$ dias.

Nesta hipótese legal, ainda que o réu tenha nomeado causídico de sua confiança, este, deixando escoar o prazo sem apresentação de peça defensiva, torna seu constituído indefeso, violando o direito ao contraditório conferido aos acusados em geral. A solução legal para a questão, reestabelecendo a paridade de armas, é a constituição da Defensoria Pública para a atuação no polo defensivo da demanda.

Da mesma forma, por meio da edição da Lei 11.449/2007, foi imposto ao Estado a obrigação de, em caso de prisão em flagrante, enviar cópia do competente auto de prisão em flagrante à Defensoria Pública, no prazo máximo de vinte quatro horas, sempre que o preso não informe o nome de seu advogado.

Neste caso, tampouco o dispositivo legal exigiu a comprovação de renda do acusado para determinar a atuação do Defensor Público, proporcionando aos desamparados de defesa técnica o devido auxílio no momento da constrição da liberdade ambulatória (FERREIRA, PRADO, online, 2009).

Diante da vulnerabilidade jurídica em que se encontra o preso em flagrante, o texto legal elegeu o órgão defensorial, mais uma vez, como garantidor de sua ampla defesa, cabendo à instituição o exercício das medidas legais cabíveis para reestabelecer seu status libertatis.

Sobre o tema, conforme Junkes (2008, p. 98), são atípicas as funçôes que a Defensoria Pública atua independentemente da condição econômica do assistido, tal qual a função, no âmbito processual penal, da defesa do réu que deixa de constituir advogado.

Isto porque na medida em que os dispositivos legais garantem o direito ao contraditório e à ampla defesa, devem também garantir instrumentos para a efetivação de uma atuação processual entre autor e réu em plano de igualdade.

Partindo das premissas do modelo garantista de implementação material dos direitos e garantias individuais e sociais do indivíduo (ROSA, 2011, p. 16), cabe ao Estado-juiz a função de fiscalização do respeito ao contraditório, mantendo Estado Acusador e Estado Defensor em posição de igualdade.

Verifica-se, neste contexto, que não é suficiente que o réu constitua advogado em sua defesa, fazendo-se necessário a atividade efetiva defensiva ao assistir o acusado. De nada adianta ao acusado uma defesa sem o arrolamento de testemunhas, realização de reperguntas, com o oferecimento de alegaçóes finais genéricas e excessivamente sucintas (FERNANDES, 2005, p. 256).

Sobre a defesa no processo penal de acusado não hipossuficiente, Caio Paiva aponta três possíveis soluçôes. Na primeira delas, aplicar-se-ia o parágrafo único do artigo 263, Código de Processo Penal, por meio do qual o juiz deve nomear um advogado dativo a ser pago pelo 
acusado. Critica-se tal hipótese em razão do risco da inexistência de uma defesa efetiva, diante da incerteza do recebimento de honorários.

A segunda solução, apontada por Firmo e Santiago como a que mais se ajusta à proposta garantista (2015, p. 80), incumbe à Defensoria Pública a missão de realizar a defesa, sendo que o acusado, por não ser hipossuficiente economicamente, realizaria o pagamento em favor de fundo próprio destinado a estruturação e aparelhamento da instituição defensorial.

Por fim, a terceira possível solução leva em consideração a hipossuficiência jurídica do acusado, garantindo-o assistência jurídica integral e gratuita, diante da aplicação do Pacto San José de Costa Rica que garante esse direito a "toda pessoa acusada de um delito", não fazendo qualquer distinção acerca da situação econômica do acusado.

Verifica-se que a adoção das soluçôes que apontam a Defensoria Pública como responsável pela atuação no caso acima citado, garantem a efetivação da defesa técnica, acompanhando as reformas legais realizadas no Código de Processo Penal citadas acima, que apresentam o órgáo defensorial como garantidor do contraditório e da ampla defesa.

\section{A DEFENSORIA PÚBLICA COMO CUSTOS VULNERABILIS NA DEFESA CRIMINAL}

Diante da função institucional da Defensoria Pública de tutela dos necessitados e desprovidos de recursos, ou "guardiã do vulnerável", cabe destacar a tripla forma de atuação da instituição (CASAS MAIA, p. 377, 2015).

A forma tradicionalmente conhecida ao atuar do Defensor Público é a que se dá enquanto representante jurídico da parte no processo, em substituição ao advogado privado, notadamente quando se está diante de um assistido economicamente hipossuficiente.

Em segundo lugar, existe a atuação da Defensoria Pública em açóes de cunho coletivo, por meio do qual a instituição atua com legitimação extraordinária, nos casos em que se está diante de uma vulnerabilidade organizacional, desde que haja lastro em suas funçóes institucionais.

Por fim, Maurílio Casas Maia propóe uma terceira forma de atuação defensorial, por meio de interveniente ou complementar, fundamentado no interesse constitucional e institucional do Estado Defensor (2015, p. 378), visando resguardar a igualdade jurídica e os direitos fundamentais do vulnerável.

Sobre o tema, o autor cita Camilo Zufelato (CASAS MAIA, 2015, p. 379), o qual defende que a Defensoria Pública poderia intervir em processos coletivos, de maneira coadjuvante, a fim de resguardar os interesses que lhes são atribuídos constitucionalmente.

A construção dessa nova forma de atuação defensorial não se limita a um âmbito específico do Direito, na medida em que se vincula com o fenômeno expansivo de acesso à justiça, o qual se relaciona diretamente com as funçóes institucionais da Defensoria Pública, 
órgão constitucionalmente incumbido de realizar a promoção dos direitos humanos e a defesa do vulnerável.

Entretanto, o foco do presente estudo é a análise da ação interveniente defensorial na seara penal, levando-se em consideração a situação de vulnerabilidade do indivíduo alvo do Estado Acusador.

$\mathrm{Na}$ esfera do processo criminal, o Ministério Público, diante da teoria das posições processuais dinâmicas, tem uma participação desigual de preponderância no processo em relação à defesa, na medida em que tem poder de fala como órgão de acusação e, também, como fiscal do ordenamento jurídico (custos legis), o que lhe possibilita reforçar seus argumentos institucionais em várias ocasióes, o que influencia na criação de precedentes judiciais favoráveis ao Estado punitivo.

Neste sentido, visualiza-se que o instituto do custos vulnerabilis se apresenta como mais um instrumento de efetivação dos direitos fundamentais a ser concretizado pelo Estado defensor, proporcionando à Defensoria Pública também reforçar os argumentos defensivos e levantar novas teses, ainda que o réu já esteja assistido processualmente.

Partindo-se deste pressuposto, e ainda destacando o nítido objetivo da persecução da igualdade jurídica, verifica-se que o modelo interveninte do órgão defensorial como custos vulnerabilis se configura como uma consequência do modelo garantista, oportunizando, de fato, a paridade de armas entre as partes, atenuando o caráter autoritário das regras processuais penais vigentes no ordenamento jurídico pátrio.

Sobre o tema, Ferrajoli admite essa hipótese de atuação pelo Defensor Público (2014, p. 537) ao destacar que cabe à instituição, quando não for o caso de suprir a ausência do representante processual privado, atuar em caráter complementar à defesa a fim de reequilibrar o combate entre acusação pública e defesa privada.

A atuação como custos vulnerabilis apresenta especial relevância diante do crescimento da importância de construção de precedentes judiciais, por meio da participação ativa e substancial da Defensoria Pública como interveniente em um feito cuja parte já é devidamente representada por advogado particular, mas que acarretará grande impacto na situação jurídica de centenas ou, talvez, milhares de pessoas que são representadas pela instituição (ROCHA, 2018, online).

Cabe destacar que a atuação da Defensoria Pública como custos vulnerabilis difere de sua intervenção como amicus curae, uma vez que não se trata de mero auxílio ao Poder Judiciário, nem estará adstrito a uma cooperação por expertise (RESSUREIÇÃO, 2018, p. 03), mas sim está atrelado à defesa de vulneráveis através do posicionamento vinculado sobre questóes discutidas em juízo.

Verifica-se, portanto, que a intervenção defensorial custös vulnerabilis tem como fim trazer aos autos, em favor do vulnerável, argumentos, informaçóes e documentos aptos a instruir o processo, de forma a possibilitar ao julgador uma cognição ampla e profunda da problemática posta, enfrentando com maior grau de certeza e confiança o mérito do pedido, sem com isso 
dispensar ou substituir o importante papel desempenhado pelo causídico particular representante judicial constituído (ROCHA, 2018, online).

Neste sentido, relevante a análise de decisóes judiciais que abordaram o tema, o que será realizado no tópico a seguir.

\subsection{A adoção do instituto do custos vulnerabilis em processos criminais}

O Habeas Corpus Coletivo n. 143641 foi impetrado pelo Coletivo de Advogados de Direitos Humanos (CADHU) perante o Supremo Tribunal Federal, havendo sido julgado em 20 de fevereiro de 2018, sob a relatoria do Ministro Ricardo Lewandowski, na Segunda Turma da Suprema Corte, com o objetivo de dar interpretação ao artigo 318 do Código de Processo Penal, que trata da possibilidade de substituição da prisão preventiva pela domiciliar, de forma que, quando o caso envolvesse mulheres ou adolescentes gestantes, puérperas ou com filhos até 12 anos ou deficientes, se subordinasse aos requisitos objetivos trazidos pela Lei da Primeira Infância (Lei 13.257/2013).

Nesta demanda coletiva, a Defensoria Pública do Estado do Ceará, dentre outras, requereu o ingresso no feito como custos vulnerabilis, diante da inegável vinculação do tema com a missão institucional do órgão. O Relator Ricardo Lewandowski admitiu o ingresso das Defensorias Estaduais como assistentes e da Defensoria Pública da Uniáo como parte autora.

No julgado, apesar de não haver sido expressamente utilizado o termo "custos vulnerabilis" pelos Ministros do Supremo Tribunal Federal, a intervenção pelos órgãos defensoriais se deu em nome próprio, como guardiá de grupo vulnerável, em demanda judicial com representante processual constituído nos autos, com fins de resguardar e promover direitos fundamentais, o que se consubstancia exatamente nesta modalidade de atuação.

Portanto, verifica-se que, naquele julgado, a atuação interveniente da Defensoria Pública, trazendo dados, argumentos e informações complementares de presídios de todo o Brasil foi de extrema relevância para o dimensionamento da problemática em questão e, consequentemente, para a prolação da decisão em favor da população feminina encarcerada, grupo de extrema vulnerabilidade jurídica, a fim de possibilitar a tutela da dignidade das crianças e mães encarceradas do Brasil (MAIA, SANTIAGO, 2019, p. 181).

A decisão prolatada neste feito teve aplicação imediata para determinar a substituição da prisão preventiva pela domiciliar de todas as mulheres presas, gestantes, puérperas ou mães de crianças com até 12 anos sob sua guarda ou pessoa com deficiência, listadas no processo pelo Departamento Penitenciário Nacional (DEPEN) e outras autoridades estaduais, enquanto perdurar tal condição, excetuados os casos de crimes praticados por elas mediante violência ou grave ameaça, contra seus descendentes, o que reafirma a situação de hipervulnerabilidade da pessoa encarcerada, demandando uma atuação direta da Defensoria Pública, independentemente da existência de advocacia privada atuante no feito. 
Já em 26 de fevereiro de 2018, na revisão criminal n. 4002158-79.2017.8.04.0000, através da Decisão do Desembargador Relator Ernesto Queiroz Alselmo Chíxaro, o Tribunal de Justiça do Estado do Amazonas adotou expressamente o entendimento da necessidade da intimação do Defensor Público Geral do Estado do Amazonas para atuar com órgão interveniente no feito, em simetria à atuação do Procurador Geral de Justiça no feito.

Assim, no mencionado julgado, entendeu-se que a intervenção da Defensoria Pública como custos vulnerabilis se consubstancia como meio de efetivação da paridade de armas, já que se, de uma banda, o órgão de acusação se manifesta duplamente, como fiscal da lei, à Defesa também lhe deve ser concedido este espaço.

Para o Desembargador, a atuação da Defensoria como guardiã dos vulneráveis se consubstancia em uma atualização da função da Defensoria Pública diante de sua definição como “essencial à função jurisdicional do Estado", prevista no artigo 134 da Constituição Federal, com a atualização do Código de Processo Penal, de 1941, com o artigo 134, Constituição Federal, trazendo um reequilíbrio na relação jurídico penal.

Para além disso, entendeu-se que esta modalidade de intervenção pelo órgão da Defensoria Pública se trata de mecanismo para abrandar a vulnerabilidade processual dos indivíduos sob a esfera do Poder Punitivo estatal, através da compensação da insuficiência legislativa quanto a instrumentos de efetivação da isonomia e paridade de armas.

\section{CONSIDERAÇÓES FINAIS}

Com base em tudo que foi delineado, e sem a pretensão de esgotar o assunto, verifica-se que a teoria do garantismo jurídico concebido por Luigi Ferrajoli propóe a superação da ideia de mera democracia formal, vinculada à vontade da maioria, para alcançar a democracia material, na qual os direitos fundamentais devem ser respeitados, efetivados e garantidos.

Partindo deste pressuposto de concretização dos direitos fundamentais descritos em nosso ordenamento jurídico, estudou-se a atuação da Defensoria Pública, como instituição constitucionalmente criada no contexto de busca ao acesso à justiça e à igualdade jurídica das partes, reconhecendo-se a instituição como manifestação do modelo garantista.

Verificou-se que diante da identificação de grupos vulneráveis e a positivação legal de sua proteção pelo Estado, fez-se necessária a expansão da atuação do órgão defensorial para transcender o mero acesso à justiça do indivíduo sem recursos financeiros, atuando como "guardião do vulnerável” sempre que se fizer necessário no caso concreto.

Neste contexto, e identificando-se o acusado de processo criminal como vulnerável diante de sua submissão ao poder punitivo estatal, defendeu-se um modelo de intervenção processual no processo criminal, de maneira coadjuvante à defesa constituída pela parte, a fim de resguardar os direitos individuais do réu que lhes são atribuídos constitucionalmente. 
À vista disso, e considerando o crescimento da importância da construção de precedentes judiciais, analisou-se o Habeas Corpus n. 143.641, que tramitou perante o Supremo Tribunal Federal, e a revisão criminal n. 4002158-79.2017.8.04.0000, que tramitou perante o Tribunal de Justiça do Amazonas, nas quais se autorizou a intervenção da Defensoria Pública como custos vulnerabilis, reforçando o caráter democrático da instituição.

Conclui-se, portanto, que diante do caráter aberto de atribuiçóes previstas constitucionalmente à Defensoria Pública, e sua finalidade de promoção de direitos humanos e defesa dos vulneráveis, a atuação como custos vulnerabilis está diretamente ligada à missão institucional do órgão, reforçando a necessidade de efetivação da paridade de armas no âmbito do processo penal.

Para além disto, a aceitação jurisprudencial da atribuição está em compatibilidade ao modelo garantista de concretização de direitos, na medida em que há previsão legal expressa de atuação do órgão sempre que houver uma situação de vulnerabilidade jurídica.

\section{REFERÊNCIAS}

ALMEIDA FILHO, Carlos Alberto S. CASAS MAIA, Maurilio. O Estado-defensor e sua legitimidade para os pedidos de Suspensão de Liminar, Segurança e Tutela Antecipada. Revista de Processo, v. 239, p. 247-261, Jan. 2015.

ARAÚJO, Francisco Firmo Barreto de. SANTIAGO, Nestor Eduardo Araruna. Garantismo Jurídico, Democracia Material e a Defensoria Pública: Contraditório e Defesa do Acusado Não Hipossuficiente. Revista Magister de Direito Penal e Processual Penal , v. 66, p. 67-84, 2015 .

BARBOSA, Rafael Vinheiro Monteiro. CASAS MAIA, Maurilio. Isonomia Dinâmica e Vulnerabilidade no Direito Processual Civil. Revista de Processo, ano 39, v. 230, abr. 2014.

BARLETTA, Fabiana Rodrigues. CASAS MAIA, Maurilio. Idosos e Planos de Saúde: Os Necessitados Constitucionais e a Tutela Coletiva Via Defensoria Pública - Reflexôes sobre o conceito de Coletividade Consumidora após a ADI 3943 e o ERESP 1192577. Revista de Direito do Consumidor, v. 106, p. 201-227, Jul.-Ago. 2016.

CADEMARTORI, Daniela Mesquita Leutchuk de. CADEMARTORI, Sérgio. A relação entre Estado de Direito e democracia no pensamento de Bobbio e Ferrajoli. Revista Sequência, n. 53, p. 145 - 162, dez. 2006.

CADEMARTORI, Luiz Henrique Urquhart. GRUBBA, Leilane Serratine. Direitos Humanos e Direitos Fundamentais: convergências entre Joaquín Herrera Flores e Luigi Ferrajoli, Revista Espaço Jurídico, Joaçaba, v. 13, n. 1, p. 157 - 176, jan./jul. 2012.

CADEMARTORI, Sérgio. Estado de Direito e Legitimidade: uma abordagem garantista.

2. ed. Campinas: Millenium, 2006. 
CAPPELLETTI, Mauro. GARTH, Bryant. Acesso à Justiça. Porto Alegre, Sergio Fabris, 1988

CASAS MAIA, Maurilio. Custos Vulnerabilis constitucional: o Estado Defensor entre o REsp no 1.192.577-RS e a PEC no 4/14. Revista Jurídica Consulex, Brasília, ano XVIII, no 417, jun. 2014, p. 55-57.

CASAS MAIA, Maurilio. Luigi Ferrajoli e o Estado Defensor enquanto magistratura postulante e Custos Vulnerabilis. Revista Jurídica Consulex, Brasília, Ano XVIII, Vol. 425, Out. 2014, p. 56-58.

CASAS MAIA, Maurilio. A Intervenção de Terceiro da Defensoria Pública nas Açóes Possessórias Multitudinárias do NCPC: Colisão de interesses (Art. 4º-A, V, LC n. 80/1994) e Posiçôes processuais dinâmicas. In: Didier Jr., Fredie; Macêdo, Lucas Buril de; Peixoto, Ravi; Freire, Alexandre. (Org.). Coleçáo Novo CPC - Doutrina Selecionada - V.1 - Parte Geral. 2a ed. Salvador: Jus Podivm, 2016, v. I, p. 1253-1292.

CASAS MAIA, Maurilio. A Defensoria Pública no novo Código de Processo Civil (NCPC): Primeira Análise. Revista de Processo, São Paulo, n. 265, p. 301-341, Mar. 2017.

CASAS MAIA, Maurilio. Litisconsórcio e Intervenção de Terceiro no novo CPC de 2015: Uma visão Geral. In: Franklyn Roger Alves Silva. (Org.). O novo Código de Processo Civil e a perspectiva da Defensoria Pública. Salvador: Jus Podivm, 2017, p. 185-206.

CASAS MAIA, Maurilio. A legitimidade coletiva da Defensoria Pública para a tutela de segmentos sociais vulneráveis. Revista de Direito do Consumidor. v. 101, p. 351 - 383, ano 24, set.-out., 2015. evista de Direito do Consumidor,

CASAS MAIA, Maurilio. A Segunda Onda de acesso à Justiça e os necessitados constitucionais: por uma visão democrática da Defensoria Pública. In: COSTA-CORREA, André L.; SEIXAS, Bernardo Silva de; SOUZA, Roberta Kelly Silva; SILVIO, Solange Almeida Holanda. (Org.). Direitos e garantias fundamentais: novas perspectivas. Birigui-SP: Boreal, 2015, p. 182-204.

CASAS MAIA, Maurilio.; SANTIAGO, Nestor, Eduaro Araruna. O Garantismo Penal, o encarceirado vulnerável e a intervenção da Defensoria Pública na Execução Penal: Custos Vulnerabilis?. Revista Brasileira de Ciências Criminais, n. 152, fev. 2019, p. 173 - 209.

CARVALHO, Luís Gustavo Grandinetti Castanho de Carvalho. FERREIRA, Alex Daniel Barreto. Um café entre a Lava-Jato vista sob a perspectiva do sistema de garantias. Revista da Faculdade de Direito da Universidade Federal de Minas Gerais, Belo Horizonte, n. 71, p. 421 - 442, jul./dez. 2017.

CARVALHO, Salo de. Penas e garantias: uma leitura do garantismo de Luigi Ferrajoli no Brasil. Rio de Janeiro: Lumen Juris, 2001

FARIAS, José Vagner de. A legitimação constitucional da atuação da defensoria pública a partir da concepçáo de necessitado para além do aspecto econômico. 2014. 116 
f. Dissertação (Mestrado) - Curso de Direito, Programa de Pós-graduação em Direitos Constitucional, Universidade de Fortaleza - Unifor, Fortaleza, 2014.

FENSTERSEIFER, Tiago. Defensoria Pública na Constituição Federal. 1. ed. Rio de Janeiro: Forense, 2017.

FERNANDES, Antônio Scarance. Processo Penal Constitucional. 4a Ed. 2005. RT:São Paulo.

FERREIRA, Luciana de Figueiredo. PRADO, Rodrigo Murad do.

O papel da Defensoria Pública no processo penal brasileiro. 2009. Disponível em: <https:// www.migalhas.com.br/o/16,MI91426,11049O+papel+da+Defensoria+Publica+no+processo+p enal+brasileiro> Acesso em: 14 dez. 2018.

FERRAJOLI, Luigi. El Derecho como Sistema de Garantias. Jueces para la Democracia. No 16 - 17. 1992

FERRAJOLI, Luigi. Garantismo y Defensa Penal o sobre la defensa pública. Em Revista das Defensorias Públicas do Mercosul, n. 01/2010

FERRAJOLI, Luigi. Direito e razáo : teoria do garantismo penal / Luigi Ferrajoli. - São Paulo : Editora Revista dos Tribunais, 2002.

IPPOLITO, Dario. O garantismo de Luigi Ferrajoli. Revista de Estudos Constitucionais, Hermenêutica e Teoria do Direito (RECHTD). No 34-41 janeiro-junho 2011

LOPES JÚNIOR, Aury; GLOECKNER, Ricardo Jacobsen. Investigação Preliminar no Processo Penal. 6. ed. São Paulo: Saraiva, 2014.

MARTINS, E. A. SANTIAGO, Nestor Eduardo Araruna. O garantismo e os precedentes da Corte Interamericana de Direitos Humanos: efeito vinculante aos Estados sob sua jurisdição.

Novos Estudos Jurídicos (Online) , v. 21, p. 569-601, 2016.

MENDES, Emerson Castelo Branco. A atuação da Defensoria Pública como garantia da efetividade da defesa do acusado juridicamente necessitado no devido processo penal constitucional. Dissertação (Mestrado) - Curso de Direito, Programa de Pós-graduação em Direitos Constitucional, Universidade de Fortaleza - Unifor, Fortaleza, 2014.

PAIVA, Caio. A Defensoria Pública e a hipossuficiência jurídica no processo penal. 2015. Disponível em: <http://www.conjur.com.br/2015-fev-24/caio-paiva-defensoria-publicahipossuficiencia-juridica\#author>. Acesso em: 13 out. 2018.

RAMOS, Glauco Gumerato. Ativismo e garantismo no processo civil: apresentação do debate. Revista Jurídica UNIJURIS, Uberaba-MG, v. 13, n. 18, p. 19 - 40, maio 2010.

REIS, Fernando Antônio Calmon. Acesso à justiça penal. Revista Brasileira de Ciências Criminais, ano 21, v. 101, p. 157 - 179, 2013. 
RESSUREIÇÃO, Lucas. A Defensoria Pública como interveniente: amicus curiae e custos vulnerabilis. Disponível em: <https://www.conjur.com.br/2018-jul-10/defensoria-publicainstituicao-interveniente> Acesso em: 15 out. 2018.

ROCHA, Amélia Soares. Defensoria Pública: Fundamentos, Organização e Funcionamento. São Paulo: Atlas, 2013.

ROCHA, Jorge Bheron. GONÇALVES FILHO, Edilson Santana. STF admite legitimidade da Defensoria para intervir como custos vulnerabilis. Disponível em $<$ https:/www.conjur. com.br/2018-abr-04/legitimidade-defensoria-intervir-custos-vulnerabilis> Acesso em: 15 out. 2018.

ROCHA, Jorge Bheron. O RE 593.818, o defensor público natural e a atuaçáo custos vulnerabilis. Disponível em <https://www.conjur.com.br/2018-abr-10/re-593818-defensorpublico-natural-atuacao-custos-vulnerabilis> Acesso em: 15 out. 2018.

ROGER, Franklyn. Princípios institucionais da Defensoria Pública. - 2 ed. - rev., atual. e ampl. - Rio de Janeiro: Forense, 2017.

ROSA, Alexandre Morais da. Garantismo Jurídico e controle de constitucionalidade material: aportes hermenêuticos. 2. ed. Rio de Janeiro: Lumem Juris, 2011.

ROSA, Alexandre Morais da. O que é garantismo jurídico? Florianópolis: Habitus, 2003.

SANTIAGO, Nestor Eduardo Araruna; SILVA, A. P. P. . Defesa efetiva, garantismo e eficiência no processo penal: o que o supremo tribunal federal tem a ver com isso. Direito Público (Porto Alegre), v. 40, p. 50-73, 2012.

SANTIAGO, Nestor Eduardo Araruna; SILVA, Ana Paula Pinto da. Garantismo penal integral e a eficiência no processo penal. Anais do XIX Congresso Nacional do Conpedi, Florianópolis, p. 9778-9793, 2010.

TARTUCE Fernanda. Igualdade e vulnerabilidade no processo civil. São Paulo: Método, 2012. p. 184.

TRINDADE, André Karam. Raízes do garantismo e o pensamento de Luigi Ferrajoli. Disponível em: <https://www.conjur.com.br/2013-jun-08/diario-classe-raizes-garantismopensamento-luigi-ferrajoli> Acesso em: 10 out. 2018.

WILLIS, Santiago Guerra Filho. Teoria constitucional dos princípios jurídicos como teoria fundamental do Direito e garantismo penal. Revista Mestrado em Direito, Osasco, Ano 06, n. 01 , p. $131-144,2006$.

ZUFELATO, Camilo. A participação da Defensoria Pública nos processos coletivos de hipossuficientes: da legitimidade ativa à intervenção ad coadjuvandum. In: RÉ, Aluísio Iunes Monti Ruggeri. Temas aprofundados de Defensoria Pública. V. 1. 2a ed. Salvador: Jus Podivm, 2013 